\title{
First report of rice bakanae disease caused by Fusarium fujikuroi Nirenberg in Turkey
}

\author{
Yeşim Eğerci ${ }^{1}$ Pervin Kınay-Teksür ${ }^{2}$ - Ayşe Uysal-Morca ${ }^{3}$ \\ Received: 9 August 2019 / Accepted: 24 June 2020 / Published online: 8 July 2020 \\ (C) Società Italiana di Patologia Vegetale (S.I.Pa.V.) 2020
}

Keywords Rice $\cdot$ Bakanae disease $\cdot$ Fusarium fujikuroi $\cdot$ Identification

Fusarium fujikuroi is a species of the Gibberella fujikuroi species complex and an important causal agent of bakanae disease on rice (Amatulli et al. 2012). Surveys were conducted in 194 fields between rice germination to maturity in Balıkesir and Canakkale, Turkey, in 2016. Bakanae disease was determined to be widespread in these provinces and the highest prevalence rate $(41.39 \%)$ was recorded in the Bandirma district. Isolates were obtained from infected plant samples, including tissues and grains. Pathogenicity tests were carried out using the susceptible rice variety, Baldo, and the plants were incubated at room temperature $\left(24 \pm 2{ }^{\circ} \mathrm{C}\right)$. In pathogenicity tests, pathogens were inoculated to seed and soil, while control seeds were soaked in sterilized distilled water and planted to sterilized soil. The seeds were inoculated by soaking into spore suspension with a density of $1 \times 10^{6}$ spore $/ \mathrm{ml}$ for $48 \mathrm{~h}$. The soil inoculation was carried out by adding $50 \mathrm{ml}$ of inoculum with the same density $\left(1 \times 10^{6}\right.$ spore/ml $)$ to the soil in each plot. The first disease symptoms appeared 10 days after inoculation. F. fujikuroi isolates caused pale green to yellowing of leaves, then thin and elongated plants. At later stages of infection, white fungal mycelia mass on the stem of plants and necrotic roots were observed, while control plants showed no symptoms. All tested 36 F. fujikuroi isolates were found to be pathogenic. Disease severity values ranged from 25 to $85 \%$. All reisolations were identified as F. fujikuroi based on morphological and molecular characters.

Yeșim Eğerci

yesim.egerci@tarimorman.gov.tr

Directorate of Plant Protection Research Institute, Bornova, Turkey

2 Department of Plant Protection, Faculty of Agriculture, Ege University, Izmir, Turkey

3 Directorate of Plant Protection Central Research Institute, Ankara, Turkey
Sporulation of isolates was abundant and colonies varied from white, greyish to dark violet in color, with or without concentric rings on PDA medium. Hyaline, obovoid to oval (0-1 septate) microconidia formed were typically clavate with a flattened base. They were agglutinated in long chains, were produced mostly from polyphialides and had an average size of 5.2-13.5 - 1.6-5.8 $\mu \mathrm{m}$. Macroconidia were hyaline, falcate to al most straight, slender, mostly 3 septate and the size of macroconidia averaged 19.6-44.1 - 1.8-4.1 $\mu \mathrm{m}$ which is consistent with $F$. fujikuroi. The PCR amplification of the TEF- $1 \alpha$ gene using primers EF $1 \backslash$ EF 2 described by O'Donnell et al. (1998) resulted in an 660-bp fragment. Sequences of the PCR products for the isolates were deposited in GenBank with the accession numbers MN091843, MN102100 and MN102101. BLAST analyses of PCR products revealed $99-100 \%$ similarity to MH699002, MH582342 and HF679028. To our knowledge, this is the first report of F. fujikuroi on rice in Turkey.

\section{References}

Amatulli MT, Sparado D, Gullino ML, Garibaldi A (2012) Molecular identification of Fusarium spp. associated with bakanae disease of rice in Italy and assesment of their pathogenicity. Plant Pathol 59: 839-844

O’Donnell K, Cigelnik E, Nirenberg HI (1998) Molecular systematics and phylogeography of the Gibberella fujikuroi species complex. Mycologia 90:465-493

Publisher's note Springer Nature remains neutral with regard to jurisdictional claims in published maps and institutional affiliations. 